\title{
A Ideia da Consideração Positiva Incondicional como Epoché: Limites e
}

\author{
Suspensão do Quê?
}

\author{
Paulo Coelho Castelo Branco* \\ Universidade Federal da Bahia - UFBA, Vitória da Conquista, BA, Brasil \\ ORCID: http://orcid.org/0000-0003-4071-3411
}

\begin{abstract}
RESUMO
Este artigo objetiva refletir os limites da ideia de consideração positiva incondicional como uma epoché, de modo questionar o que é suspenso. Para isso, apresenta as noções husserliana de epoché e rogeriana de consideração positiva incondicional. Depois, situa as origens das apropriações da epoché pela clínica fenomenológica e pela abordagem rogeriana. Posteriormente, desenvolve reflexões que demarcam alguns limites entre essas atitudes. Conclui que a consideração positiva incondicional poderia ser a suspensão dos juízos que procedem dos afetos de simpatia, apatia e antipatia. Em uma meta-teoria, isso serve para descrever o procedimento de escuta não-diretiva sem julgamentos, a qual parte da assimilação de uma visão de mundo oriunda da Fenomenologia, mas não se trata de uma Fenomenologia pura, filosofia fenomenológica ou Psicologia Fenomenológica. A consideração positiva incondicional é uma atitude de escuta que se desenvolveu fora do método fenomenológico e não precisa ser legitimada pela epoché, não propõe nenhuma redução, não suspende a crença na tendência à autorrealização e sua suspensão não é fenomenológica.
\end{abstract}

Palavras-chave: Carl Rogers, fenomenologia, psicologia humanista, psicologia fenomenológica, terapia centrada no cliente.

\section{The Unconditional Regard Idea as Epoché: Limits and Suspension of}

\section{What?}

\begin{abstract}
This article aims to reflect the limits of the idea of unconditional positive regard as an epoché, to question what is suspended. It presents the husserlian notion of epoché and the rogerian concept of unconditional positive regard. Then, it situates the origins of the epochés appropriations by the phenomenological clinic and by rogerian approach. Posteriorly, it reflections that demarcate some limits between these attitudes. It concludes that the unconditional positive regard could be the suspension of judgments that proceed from the affections of sympathy, apathy, and antipathy. In a meta-theory, this serves to describe the non-directive listening procedure without judgments, which would come from the
\end{abstract}


assimilation of a worldview from Phenomenology, but it is not a pure Phenomenology, phenomenological philosophy or Phenomenological Psychology. The unconditional positive regard is a listening attitude that has developed outside the phenomenological method, and does not need to be legitimized by epoché, does not propose any reduction, does not suspend the belief of the self-actualization tendency and its suspension is not phenomenological.

Keywords: Carl Rogers, phenomenology, humanistic psychology, phenomenological psychology, client centered therapy.

\section{La Idea de la Consideración Positiva Incondicional como Epoché: ¿Límites}

\section{y Suspensión de Qué?}

\section{RESUMEN}

Este artículo objetiva reflejar los límites de la idea de la consideración positiva incondicional como una epoché, para cuestionar lo que es suspendido. Para esto, presenta las nociones husserliana de epoché y rogeriana de consideración incondicional. Después, sitúa los orígenes de las apropiaciones de la epoché por la clínica fenomenológica y por el enfoque rogeriano. Posteriormente, desarrolla reflexiones sobre algunos límites entre estas actitudes. Concluye que la consideración incondicional podría ser la suspensión de los juicios que proceden de los afectos de simpatía, antipatía y apatía. En una meta teoría, esto sirve para describir el procedimiento de escucha no-directiva sin juicios, que parte de la asimilación de una visión de mundo fenomenológica, pero no es una Fenomenología pura, Filosofía Fenomenológica o Psicología Fenomenológica. Consideración incondicional es una actitud de escucha que se ha desarrollado fuera del método fenomenológico y no necesita legitimarse por la epoché, no propone ninguna reducción, no suspende la creencia en la tendencia a la autorrealización y su suspensión no es fenomenológica.

Palabras clave: Carl Rogers, fenomenología, psicología humanista, psicología fenomenológica, terapia no dirigida.

No Brasil, há uma profusão de psicólogos que compreendem a Fenomenologia como uma abordagem rogeriana (Orengo, Holanda, \& Goto, 2020), ainda que a filosofia fenomenológica não constitua uma base epistêmica de Rogers (Moreira, 2009; Castelo Branco \& Cirino, 2017; Castelo Branco, 2019) e existam produções que examinam as apropriações, por vezes polêmicas, da Fenomenologia pela Psicologia, sobretudo a Humanista (Goto, 2015, Gomes \& Castro, 2010; Castro \& Gomes, 2011; Goto \& Feijoo, 2017).

É nesse panorama que este artigo aponta para a existência da circulação de uma ideia relacionada à articulação entre a atitude de epoché (suspensão fenomenológica), cunhada por Edmund Husserl (1913/2006), e a atitude de consideração positiva incondicional, 
desenvolvida por Carl Rogers (1957/2008). Em específico, nota-se que uma das manifestações dessa ideia decorre de leituras da consideração positiva incondicional como uma suspensão fenomenológica (Amatuzzi, 1989; Forghieri, 1993; Holanda, 1997; Moreira, 2009; Amatuzzi \& Carpes, 2010). Convém ressaltar que Husserl e Rogers construíram os seus pensamentos e as suas propostas psicológicas em épocas e locais diferentes. Ambos não se conheceram nem se citaram ou referiram (Castelo Branco \& Cirino, 2017). Portanto, não foram eles que estabeleceram a mencionada articulação, mas sim os seguidores de Rogers que enxergaram nele uma influência fenomenológica (Moreira, 2009).

Pressupondo que as mencionadas atitudes seriam uma fonte para creditar a abordagem rogeriana como fenomenológica, objetiva-se refletir os limites da ideia da consideração positiva incondicional como uma atitude fenomenológica de epoché. Questiona-se: seria a consideração positiva incondicional uma epoché fenomenológica? Assim, inicialmente, fundamentam-se as noções de epoché e consideração positiva incondicional. Em seguida, apresentam-se as origens da ideia da epoché como uma atitude terapêutica, nos campos da clínica fenomenológica e da abordagem humanista de Rogers. Por fim, discutem-se alguns pontos sobre os limites dessa articulação do legado de Rogers com o de Husserl.

\section{Da Atitude Natural à Epoché como o Princípio da Atitude Fenomenológica}

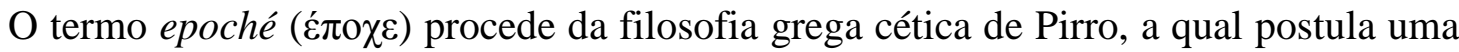
imperturbabilidade a partir da suspensão dos juízos ou abstenção dos valores de todas as coisas que levam uma pessoa a aceitar ou recusar dogmaticamente algo (Sokolowski, 2000/2010). Contudo, para Husserl (1913/2006) o raciocínio da epoché fenomenológica parte da tese da orientação natural, em que se tem uma consciência de que o mundo e as coisas que estão nele existem por si só, para em seguida colocar isso fora de circuito. A atitude natural se dá nas esferas da intuição imediata, do eu e da experiência. Essas coisas podem ser materiais, outras pessoas, animais, estados mentais, ideias, representações, abstrações, acontecimentos etc. Mesmo que esses objetos não estejam imediatamente presentes no campo perceptivo ou não sejam diretamente conhecidos ou, ainda, sejam pouco conhecidos, há uma impressão de que eles estão disponíveis e existem independentes da vontade de quem se volta para eles.

Assim, o mundo, em suas nuances e sucessões espaciais e temporais, e os seus objetos, em seus valores, propriedade materiais e práticas, são percebidos e vividos como meras coisas que estão naturalmente aí (Husserl, 1913/2006). O mesmo ocorre com a experiência imediata que se tem do mundo como um contexto/horizonte para todas essas coisas. Eis os elementos 
estruturantes da atitude natural, a qual demarca uma crença de aceitação do mundo e das coisas que estão nele como dados independentes da consciência (Sokolowski, 2000/2010).

Em termos cartesianos, Husserl (1913/2006) entende a atitude natural como um cogito irrefletido e que não é objeto para um eu. Acontece que essa orientação natural demarca um estado de preconcebimento que é anterior a toda teoria que se possa fazer sobre o objeto versado. Quando há uma teoria (um conhecimento) sobre um objeto, esta parece ser pré-dada. Essa orientação natural, segundo Husserl (1913/2006), está presente nas ciências e na filosofia. Isso é a "porta de entrada" para promover uma modificação radical dessa direção e desenvolver um conhecimento refletido sobre o objeto, entendido agora como uma correlação entre mundo e eu. Nesse ponto, Husserl (1913/2006; 1929/2001) critica as meditações cartesianas em seu caráter metodológico basilar, pois tal autorreflexão coloca em dúvida os juízos tomados como verdadeiros e dados, porém não dúvida do ato de duvidar. Para Husserl (1913/2006), o eu é livre para duvidar e é ao simular uma dúvida sobre algo que se tem a consciência do que se duvida, evidenciando-se outro modo de pensar.

Destarte, a consciência do ato de tentar duvidar, que é diferente de simplesmente duvidar, provoca o esforço de identificar o objeto da dúvida, examinar o que está dado nisso (valores, juízos e sentidos, por exemplo) e suspender isso para contemplar o objeto em sua manifestação. A dúvida em sua orientação natural não implica em um esforço e uma escolha, mas a tentativa de duvidar demarca um esforço intelectivo (Sokolowski, 2000/2010). Logo, acontece um giro fenomenológico que não implica em uma privação, mas outro modo de tomar consciência do objeto em que surgem os entrelaçamentos que lhe constituem como um

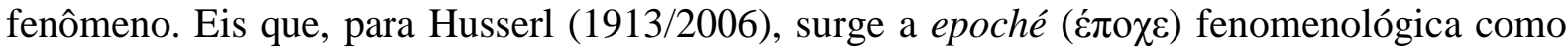
um princípio metodológico em que

Colocamos fora de ação a tese geral inerente à essência da orientação natural (...) todo este mundo natural que está constantemente "para nós aî", "a nosso dispor", e que continuará aí como "efetividade" para a consciência, mesmo quando nos aprouver colocar entre parênteses. (...) então não nego este "mundo", não duvido de sua existência como se fosse cético. (...) eu não faço absolutamente uso algum de suas validades. Não me aproprio de uma única proposição sequer delas, mesmo que de inteira evidencia, (...) nenhuma me oferece alicerce (...). Só posso admiti-la depois de lhe conferir parênteses (Husserl, 1913/2006, pp. 81, itálicos do autor).

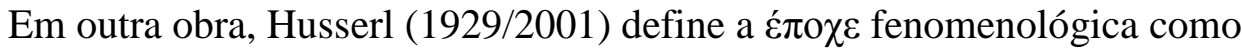


(...) uma colocação entre parênteses (...) pelo qual percebo o eu puro (...) pelo qual todo mundo objetivo existe para mim (...) para minha consciência num cogito semelhante. Em consequiência, (...) a existência natural do mundo (...) pressupõe uma existência em si anterior, a do ego puro e de suas cogitationes. (...) É por isso que o

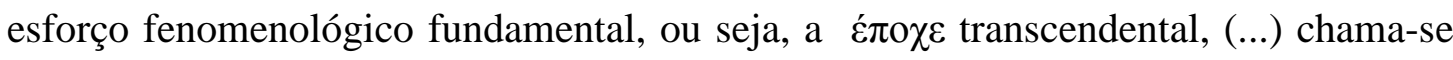
redução fenomenológica transcendental (Husserl, 1929/2001, pp. 38-39, itálicos do autor).

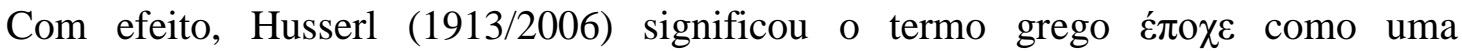
"suspensão", "abstenção" ou "colocação entre parênteses" da atitude natural (Natürliche Einstellung), de modo que a mudança de orientação natural ficou popularizada como uma “atitude fenomenológica” (Sokolowski, 2000/2010). Assim, a epoché fenomenológica é uma suspensão dos juízos (pensamentos e valores) já existentes sobre o fenômeno para adentrar a esfera de como se ter a consciência de algo (noesis) e como apreender aquilo de que se tem consciência (noema) (Husserl, 1913/2006). A necessidade dessa postura advém de uma crítica de Husserl à atitude natural presente no naturalismo, o qual postulava que todo conhecimento está subordinado a dados imanentes de uma realidade exterior existente por si só, e no psicologismo, o qual defende que todos os dados de mundo são representações psíquicas (Goto, 2015).

A epoché seria, pois, uma via de retorno às coisas mesmas, isto é, uma postura ingênua ante o fenômeno que permite acessá-lo por ele próprio, de modo a evidenciar o caráter subjetivo e objetivo do conhecimento e da consciência. Fenômeno é entendido como tudo aquilo (objeto material, ideal ou acontecimento) que se mostra para a consciência de alguém. Trata-se de uma identificação dos juízos sobre esses fenômenos antes de suspendêlos em prol de uma observação desinteressada que demarca um método puramente reflexivoanalítico (Goto, Holanda, \& Costa, 2018). Ao sustentar isso em um momento noemático, suspendem-se os juízos pessoais que emanam da experiência do sujeito para apreender os sentidos essenciais (invariáveis) do fenômeno refletido, que permanecem diante das variações de ideias sobre o que lhe constitui e caracteriza. No momento noético, retorna-se para o que a consciência do sujeito atribui de sentidos ao fenômeno, reconhecendo a dimensão transcendente de sua experiência (Husserl, 1913/2006). O resultado do que foi obtido pelo método é uma Filosofia de base fenomenológica, pois foi obtida pelo método proposto por Husserl em uma Fenomenologia pura. Esse conhecimento pode servir como uma linha de 
discussão que expande a experiência (sensível e racional) sobre o fenômeno versado, a partir das vivências intencionais dispostas nos momentos aludidos (Goto et al., 2018).

Dessa breve explicação, vale ressaltar que a ideia de um fenômeno que é depurado por uma atitude fenomenológica, composta pela epoché e pelas reduções decorrentes, trata-se de uma visada filosófica que não precisa de comprovação empírica ou experimental, tampouco trabalha com sujeitos empíricos ou experimentais, pois se ocupa de uma meditação (autorreflexão criteriosa) relacionada à ideia de algo (Goto, 2015).

Portanto, os atributos da epoché e das reduções constituem uma Fenomenologia pura, que é o método para rumar de uma atitude natural para uma atitude fenomenológica, a qual possibilita outro conhecimento (filosofia fenomenológica) sobre o que supostamente estava dado (Goto et al., 2018). Alguns seguidores e estudiosos de Husserl, influenciados por esse método, desenvolveram filosofias concernentes a variados fenômenos como justiça, ser, religião, literatura, ética, empatia, percepção, emoção etc. (Goto, 2015).

\section{A Consideração Positiva Incondicional como uma Atitude e Condição Terapêutica}

Em uma crítica aos modelos vigentes, nos EUA, de aconselhamento psicológico e psicoterapia que centravam na figura do psicólogo toda a direção, condução e responsabilidade pelo processo terapêutico, Rogers (1959/1977) estabeleceu uma perspectiva de consulta psicológica entendida como não-diretiva. Esta confere ao cliente maior autonomia para lidar com a sua situação problema e tensões decorrentes dela, a partir do contato com a sua experiência e organização de self. Com base nisso, Rogers desenvolve intervenções em aconselhamento, psicoterapia, trabalhos grupais e educacionais (Castelo Branco, 2019).

Rogers (1959/1977; 1961/1997) foi cobrado pela Associação Americana de Psicologia para sistematizar e operacionalizar os seus achados clínicos decorrentes de suas práticas e pesquisas experimentais e empíricas sobre Psicoterapia. Ao longo de suas obras, é possível notar a importância de um componente relacional que possibilita uma atmosfera terapêutica de aceitação e fomento das expressões da experiência do cliente, sem a interferência dos juízos de valores que emanam do terapeuta e dos prejuízos que isso acarreta ao processo do cliente (Araújo \& Freire, 2014). Por isso, essa atitude clínica culminou na noção de consideração positiva incondicional que expressa um posicionamento por parte do terapeuta de não julgar ou criticar os pensamentos e as expressões do cliente, fazendo-o se sentir ele mesmo e lhe possibilitando adentrar os elementos de sua experiência a partir dos seus 
próprios juízos e valores. Trata-se de uma postura de respeito ao outro e de lhe permitir contatar suas vivências de problemas sem avaliações externas (Almeida, 2009).

Foi Stanley Standal, doutorando de Rogers, que defendeu, em 1954, a tese sobre a necessidade de consideração positiva incondicional na terapia. Este trabalho empírico (a partir do emprego de questionários no decorrer de sessões clínicas), estabelecido em um delineamento quase experimental de pesquisa com pessoas submetidas à terapia centrada no cliente (Rogers, 1961/1997), contribuiu com a alcunha do termo e foi citado por Rogers (1959/1977) para aludir que a personalidade é constituída por juízos de valores que procedem de outras pessoas e afetam suas autopercepções, autoconceitos e funcionamentos no ambiente.

A noção de consideração positiva incondicional está pioneiramente concernida em um artigo de Rogers (1957/2008) sobre as condições necessárias e suficientes para mudança terapêutica da personalidade. Rogers (1959/1977) estabelece seis princípios (variáveis independes) que se articulados ordenam um processo clínico que provoca tal modificação (variáveis dependentes), a saber: (1) que haja um contato entre terapeuta e cliente; (2) que este vivencie um estado de incongruência; que o terapeuta vivencie estados de congruência (3), consideração positiva incondicional (4) e compreensão empática (5) em relação ao cliente; (6) que este experimente e perceba que o terapeuta está tentando considerá-lo e compreendê-lo.

Assim, a atitude de consideração positiva incondicional demarca que o terapeuta não estabelece ou impõe condições e valores sobre o que o cliente expressa. Recorrendo ao pragmatismo de John Dewey, Rogers (1959/1977) entende que essa condição se trata de uma a-preci-ação (ato de não colocar preço) no que o outro sente, pensa e faz (Almeida, 2009; Castelo Branco, 2019). É um cuidado de não enquadrar o cliente naquilo que o terapeuta quer que ele seja, pense e faça. Essa atitude é estabelecida em termos de grau, como uma tentativa e um constante exercício de atenção do terapeuta diante de si e do que o outro lhe provoca em termos de juízos e valores (Araújo \& Freire, 2014). Salienta-se que essa atitude é circunscrita à crença e valor (a priorístico) de que todo organismo é capaz de realizar suas potencialidades de crescimento, desde que elas sejam acessadas e contatadas pelo cliente, a partir de sua própria experiência. Assim, a condição positiva incondicional é um princípio relacional que facilita a manifestação dessa tendência autorrealizadora no cliente (Rogers, 1959/1977).

Em suma, considerar o outro incondicionalmente significa não julgá-lo para analisar a pessoa em si e por si, deixando um caminho livre para a espontaneidade que emerge na relação e para acessar os conteúdos dessa experiência, via compreensão empática. Para além do contexto clínico, nas esferas relacionais familiares, grupais e educacionais, Rogers (1959/1977) ampliou essa atitude em termos de aceitação da pessoa como alguém de valor 
incondicional, que pode exercer a mesma postura com os outros indivíduos. Decorre disso, relações mais criativas, autênticas, proximais e de maior estima pelo outro (Almeida, 2009).

\section{Situando a Ideia da Atitude Fenomenológica como uma Postura Clínica}

É possível identificar diversas influências da Fenomenologia na Psicopatologia, Psiquiatria e Psicoterapia (Gomes \& Castro, 2010; Moreira, 2010). Entretanto, a apropriação da Fenomenologia de Husserl é perpassada por transformações entendidas como polêmicas, pelas ressalvas de (Gomes \& Castro, 2010; Castro \& Gomes, 2011; Goto \& Feijoo, 2017): transpor uma Fenomenologia pura para uma Fenomenologia aplicada, empírica ou experimental; usar uma filosofia fenomenológica como recurso hermenêutico para implicar outros quadros explicativos e analíticos, além das vertentes psicanalíticas e psiquiátricas, atrelando-as às filosofias existenciais.

Com efeito, o exercício da epoché e das reduções trazem contribuições para o campo da clínica psicológica, no sentido de prover um olhar e uma escuta que são meneados pela experiência pré-reflexiva e anterior a cisão sujeito-objeto, evidenciando a intersubjetividade existente entre o paciente e o seu sintoma/objeto de sofrimento (Gomes \& Castro, 2010). Além disso, a atitude fenomenológica que perpassa a epoché possibilita um trato do fenômeno clínico como ele se apresenta em sua totalidade, longe de possíveis reducionismos incutidos pelo direcionamento imposto pelas teorias prévias ao encontro e pelos pré-conceitos do terapeuta. Sem essas pressuposições clínicas, emergem descrições do que ocorre nas vivências do paciente, entendendo que todas elas são dotadas de sentido e se correlacionam com os objetos que estão no mundo (Moreira, 2010).

Assim, a clínica fenomenológica se ancora em dimensões existenciais, pois o terapeuta parte das questões e problemas de lançamento do paciente ao/no mundo em uma relação intersubjetiva com ele (Gomes \& Castro, 2010). Esse apontamento decorre de ponderações seminais acerca da atitude fenomenológica na clínica, sobretudo pelos aportes de Karl Jaspers, Ludwig Binswanger e Merdad Boss (Moreira, 2010), na Europa, e Rollo May (1979/2000), nos EUA, os quais apontavam as possibilidades e os limites de empregar uma atitude fenomenológica ante o outro na clínica (Gomes \& Castro, 2010). Essa contenda advém do argumento de que a Fenomenologia pura não foi concebida originalmente para tratar de relações terapêuticas e que, por isso, em alguma redução se perderia o fluxo das vivências atuais expressas na relação, seja pelo terapeuta seja pelo paciente, o que torna uma abordagem fenomenológica da psicoterapia algo em constante construção (May, 1979/2000). 
Além disso, o clínico, dito fenomenológico puro, não precisa estar em contato com outro sujeito empírico, dado que o acesso ao fenômeno ocorre mediante uma autorreflexão de suas ideias e sentidos (Goto, 2015). Por essa razão, muitos filósofos e psicólogos acabam se aproximando de outras fenomenologias, sobretudo existenciais, que embora reconheçam as influências de Husserl, podem ser questionados acerca do real emprego dos recursos da epoché e das reduções eidéticas e transcendentais, pela razão que (Zahavi, 2019): não especificam o uso disso; parecem recorrer ao pensamento ou a figura do criador da Fenomenologia mais para legitimar um rigor filosófico do que para empreender uma análise fenomenológica, o mesmo ocorrendo com as psicologias que buscam desenvolver uma Fenomenologia não-filosófica e aplicada as dimensões empíricas e experimentais.

Com efeito, as clínicas fenomenológicas parecem se focar mais no uso de uma epoché sem redução e se inspiram em pressupostos teóricos e filosóficos fenomenológicos como esteio hermenêutico para pensar os fenômenos psicopatológicos. Contudo, isso se distancia da proposta de uma Fenomenologia pura (Zahavi, 2019). Além disso, a escuta clínica, desde Freud, considera a importância de uma atenção despretensiosa em relação ao que o paciente apresenta, justamente para considerar suas dimensões idiossincráticas para em seguida interpretá-las (Gomes \& Castro, 2010). Portanto, nem todo foco descritivo da experiência pelo o que ela apresenta precisa de ou seja uma epoché (Zahavi, 2019).

\section{Situando a Ideia da Epoché como uma Atitude de Consideração Positiva Incondicional}

Considera-se que o axioma rogeriano da não-diretividade, posteriormente operacionalizado pela condição de consideração positiva incondicional, foi pioneiramente aproximado e pensado como uma postura fenomenológica no artigo Phenomenological concepts in nondirective therapy, escrito por Arthur Combs (1948), um doutorando que trabalhou com Rogers nos anos de 1940. Entretanto, Combs (1948) não situa nenhuma tradição clínica fenomenológica para lançar tal argumento, mas se atém a uma postura descritiva que deixa o cliente livre para expor os seus problemas e possibilitar que o psicólogo se aproxime do seu campo perceptivo para entender sua organização de personalidade.

O próprio Rogers (1961/1997) reconheceu uma aproximação tardia do seu pensamento com a Fenomenologia a partir dos apontamentos de alguns alunos, dos quais se destaca Eugene Gendlin, mas não desenvolveu uma clínica de base ou inspiração fenomenológica, não empregou uma metodologia empírica fenomenológica nem elaborou uma filosofia fenomenológica, conquanto tenha sido simpático à Fenomenologia como (Castelo Branco \& 
Cirino, 2017): um movimento estadunidense de pensamento paradigmático alternativo às ciências do comportamento; uma base para o desenvolvimento da Psicologia HumanistaExistencial; uma influência para a elaboração do método fenomenológico empírico como estratégia de pesquisa qualitativa e empírica em Psicologia.

É interessante pontuar que Rogers foi academicamente próximo de Adrian Van Kaam, o criador do método fenomenológico empírico, participando da sua banca de doutorado e orientando o seu pós-doutorado. Em 1958, Van Kaam defendeu a tese The experience of really felling understood by a person: a phenomenological study of the necessary and sufficient constituents of this subjective experience as described by 365 subjects. Atenta-se para as seguintes ideias: a experiência de se sentir realmente compreendido por uma pessoa; e os constituintes necessários e suficientes da experiência subjetiva conforme descrita por sujeitos. Embora Van Kaam (1959/2018) recorra à filosofia fenomenológico-existencial como premissa do método, percebe-se uma leitura implícita do pensamento de Rogers, em relação às condições necessárias e suficientes para considerar a experiência alheia e compreendê-la. Conforme Van Kaam (1959/2018), os resultados disso seriam úteis para pensar os problemas de terapia, aconselhamento e personalidade. Curiosamente, as datas do fechamento e publicação do trabalho de Van Kaam são próximas da divulgação do artigo de Rogers (1957/2008) sobre as mencionadas condições terapêuticas.

Destarte, os apontamentos expressos anteriormente argumentam que a aproximação de uma atitude fenomenológica com a postura clínica de Rogers acontece desde o início do seu pensamento. Não à toa, alguns psicólogos brasileiros (Forghieri, 1993; Holanda, 1997; Moreira, 2009; Amatuzzi \& Carpes, 2010) perceberam uma possível articulação entre as atitudes fenomenológica e de consideração positiva incondicional, e passaram a pensá-las e desenvolvê-las segundo uma Psicologia Humanista-Fenomenológica, a despeito de o próprio Rogers (1957/2008, 1959/1977) não situar sua condição relacional com base em alguma influência fenomenológica. A proposta de considerar a experiência alheia por ela própria em sua totalidade sem julgá-la, para captar os sentidos e juízos que emergem da pessoa, foi entendida como uma postura fenomenológica de suspensão. Esta coloca o terapeuta em uma posição ingênua perante o cliente, de modo a retirar de ação suas teorias pré-concebidas sobre o problema e seus julgamentos sobre sua experiência.

Acredita-se que, no Brasil, Yolanda Forghieri (1993) foi a pioneira em tal aproximação e releitura da consideração positiva incondicional à luz da epoché. Depois dos estudos doutorais na Universidade de São Paulo, em 1973, sob a orientação de Oswald de Barros Santos, seguindo a sugestão de Dante Moreira Leite, Forghieri (1993) se aproximou 
das leituras de Binswanger e Boss, que lhe apresentaram a noção husserliana de epoché. A partir disso, nos anos de 1970, Forghieri (1993) disseminou a suspensão fenomenológica com base em suas leituras de Rogers, formando e influenciando gerações de psicólogos humanistas brasileiros. Mesmo reconhecendo que Rogers não procede da Fenomenologia, Forghieri (1993) argumenta que a atitude de consideração positiva incondicional pode ser entendida como uma atitude fenomenológica, no sentido de proporcionar que o terapeuta se abstenha dos seus juízos, teorias e valores para deixar a experiência do cliente se mostrar e, posteriormente, adentrá-la via compreensão empática.

Hoje é sabido e divulgado que Rogers não possui influências das filosofias fenomenológicas (Moreira, 2009), sobretudo de Husserl (Castelo Branco \& Cirino, 2017), e que tal aproximação é problemática (Goto, 2015) e incoerente, de um ponto de vista epistemológico em relação à concepção rogeriana de experiência consciente, que é funcionalista-pragmatista (Castelo Branco \& Cirino, 2016). Contudo, o desenvolvimento da ideia de Forghieri está lançado. Para exemplificar, destacam-se os trabalhos de: Holanda (1997), o qual demarca que uma atitude fenomenológica na abordagem centrada na pessoa acena para uma postura terapêutica desprovida de ideias apriorísticas que a torna mais aberta ao aqui-e-agora; Moreira (2009), que percebe em alguns trechos escritos por Rogers sugestões de aproximações com a atitude fenomenológica, ocasionando uma perspectiva pós-rogeriana fenomenológica-existencial; Amatuzzi e Carpes (2010), os quais argumentam que a terapia rogeriana serve como uma passagem da atitude natural para a atitude fenomenológica, a partir das implicações fenomenológicas de Husserl.

\section{Os Limites de Pensar a Consideração Positiva Incondicional como uma Epoché: Afinal, o que é Suspendido pela Atitude Rogeriana?}

Do transcurso empreendido até então, agora é possível estabelecer algumas linhas de pensamento relacionadas aos limites de pensar a consideração positiva incondicional como uma epoché (suspensão fenomenológica). As seguintes reflexões, por conseguinte, intencionam listar alguns apontamentos ao cenário brasileiro de Psicologia Humanista Centrada na Pessoa e Psicologia Fenomenológica.

1. Pode-se entender a aproximação da consideração positiva incondicional com a epoché pelo argumento de que ambas são atitudes. Salienta-se que Husserl (1913/2006) não

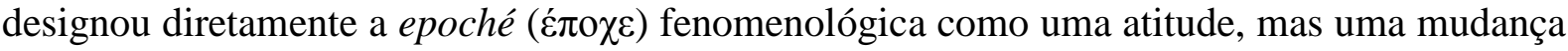
da orientação natural. Isso que pode gerar confusões ao se conceber uma epoché que não seja 
fenomenológica, mais próxima da ideia cética grega de viver sem emitir juízos de valores, mas que não intenciona uma mudança da orientação natural para examinar os polos noéticos e noemáticos do fenômeno. Como atitudes, ambas partem de um esforço perceptivo de se voltar para o que se apresenta a experiência em termos de juízos, pensamentos e pré-conceitos. Porém, somente o entendimento teórico e intelectual do que sejam elas não é o suficiente para cumprir com o que essas atitudes propõem, a saber: a epoché fenomenológica estabelece um princípio autorreflexivo para examinar, via reduções, os polos da intencionalidade que permeiam um fenômeno; a consideração positiva incondicional se vincula a outras condições (congruência e compreensão empática) que são sustentadas para possibilitar o acesso da experiência alheia num âmbito de intervenções terapêuticas individuais, grupais ou educacionais. Cada atitude depende da experiência de quem as sustenta e, no âmbito terapêutico, servem como recurso/critério para contatar outras experiências, possibilitando a emergência das singularidades que se apresentam.

2. Na esfera filosófica, as meditações de Husserl (1931/2001) forçam o intelecto do leitor a acompanhar suas autorreflexões, no sentido de promover o exercício fenomenológico. Por outro lado, Rogers (1959/1977) não parte de uma estrutura racional e lógica, mas empírica para treinar terapeutas no sustento das atitudes de congruência, consideração positiva incondicional e compreensão empática, mediante a observação de gravações clínicas, o estabelecimento de respostas frente às demandas expressas e o uso de questionários para avaliar se houve ou não movimento na pessoa. Posteriormente, esse treino passou a acontecer em uma esfera grupal e inter-relacional mais direta entre os participantes que vivenciam essas atitudes (Castelo Branco, 2019). Com efeito, a epoché e a consideração positiva incondicional demandam esforço de quem as praticam, mas são exercidas em contextos diferentes.

3. A empreitada de Rogers (1961/1997) é amparada por pesquisas experimentais e instrumentos psicrométricos para fundamentar e legitimar suas atitudes terapêuticas. Isso vai à contramão das críticas de Husserl (1929/1992) às ciências psicológicas e da sua proposta de epoché que não requer tais aparatos para ser validada e servir de base para uma Fenomenologia pura e uma Psicologia Fenomenológica (Goto et al., 2018). O projeto de Husserl não foi o projeto de Rogers e este não precisou recorrer à Fenomenologia ou partir dela para legitimar, fundamentar e aplicar o seu conhecimento.

4. Procedendo de uma crítica ao psicologismo e naturalismo comum as ciências da época, Husserl (1913/2006) propôs as reduções, retomando a concepção filosófica estoica

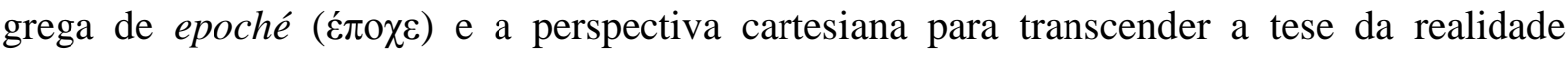
existente em si e buscar um conhecimento que suspenda as crenças psicologistas e 
naturalistas, evidenciando a os extratos da consciência e do que a transcende. Rogers (1959/1977) procede de uma perspectiva pragmatista para compor a atitude de consideração positiva incondicional, dado que recorre ao pensamento de Dewey para aludir uma valorização da experiência pelo o que emerge dela, reconhecendo-a como um lócus de verdade e conhecimento válido pelo qual o psicólogo deve partir para realizar apreensões das demandas do cliente e proceder com suas intervenções. Assim como a Fenomenologia, a filosofia pragmatista, também, propõe uma superação dos racionalismos e empirismos nas ciências, entretanto, não emprega um método de rigor à exemplo de Husserl, mas parte de um exercício intelectivo para (re)conhecer as múltiplas realidades que coexistem e interagem no mundo, dada a consideração de que todas as experiências produzem realidades pessoais e compartilhadas (Feijoo, 2013; Castelo Branco \& Cirino, 2016).

5. Além disso, Rogers procede de uma tradição psicoterapêutica pós-freudiana horneyana, também compartilhada por Standal, a qual argumenta que a introjeção de valores alheios sem as devidas apropriações e considerações experienciais são fontes de desorganização da personalidade (Castelo Branco, 2019), por isso a escuta clínica deve minimizar as influências dessas introjeções por parte do terapeuta. Diferente das correntes pós-freudianas de estirpe fenomenológica-existencial, as posturas clínicas horneyana e rogeriana não trabalham com a epoché ou aludem a esta atitude. Assim como salienta Zahavi (2019), a insistência de enquadrar a epoché fenomenológica para ajudar a compreender melhor a experiência do paciente, ao invés de deixar os pesquisadores e clínicos se engajarem nos fenômenos tal como eles se apresentam, gera mais debates e intrigas, dado que há equívocos no entendimento do termo e reducionismos na proposta do uso da atitude. Consoante ao autor supracitado é errôneo achar que toda preocupação com a descrição da experiência e rejeição de quadros explicativos prévios ao que ela apresenta é uma epoché e necessita do uso das reduções fenomenológicas.

6. Ocorre que o método fenomenológico tem como ponto de partida a suspensão da tese do mundo existente por si, não estabelece hipóteses e visa identificá-las para, em seguida, poder neutralizá-las, ou seja, suspendê-las; a visada metodológica de Rogers parte de hipóteses pré-estabelecidas e constantemente colocadas à prova pela pesquisa e experiência clínica, que estabelece novas hipóteses. Rogers (1959/1977) não busca suspender a tese do mundo ou da existência de uma realidade em si nem põe isso em dúvida, por isso procura identificar ordens e princípios que constituem a personalidade e as relações interpessoais. Ademais, a atitude rogeriana não suspende a crença de que todo organismo tende ao crescimento e à autonomia, em função da força biológica expressa pela tendência à 
autorrealização. A consideração positiva incondicional incensa essa força pelo não julgamento e pelo fomento ao contato do cliente com a sua experiência organísmica direta e dos valores que emergem dela e correspondem ao seu self (Castelo Branco, 2019). A suspensão disso descaracterizaria essa base do pensamento rogeriano que não muda de orientação em relação à crença na tendência à autorrealização. Portanto, a epoché fenomenológica e a consideração positiva incondicional são de ordens diferentes.

7. Considerando que a epoché é um elemento constituinte da vasta filosofia husserliana, que conta com outras noções, entende-se que esse componente foi assimilado por variados saberes filosóficos e diversas psicologias aplicadas, empíricas e experimentais (Goto, 2015). Stein (1930-1931/2019) argumenta que a Fenomenologia pura de Husserl apresenta um método que proporciona uma filosofia fenomenológica e se desdobra, também, em uma visão de mundo que é apropriada por outros saberes. Nesse sentido, encontra-se uma resposta ao apontamento de Zahavi (2019) de que nem todas as filosofias e psicologias ditas fenomenológicas explicitam seu ponto de partida pela epoché e pelas reduções, pois elas se apropriam de elementos do pensamento de Husserl e não decorrem exatamente do seu percurso metodológico. Somente a epoché, por ela própria, não é o suficiente para produzir uma Fenomenologia pura, uma filosofia fenomenológica ou uma Psicologia Fenomenológica. Nesse sentido, uma pressuposição equivocada da epoché, para fundamentar o fenômeno de aceitar e considerar incondicionalmente o outro, implica em apenas assimilar uma visão de mundo da Fenomenologia, não tornando o legado rogeriano uma abordagem fenomenológica.

Muitas das críticas da Fenomenologia sobre as insuficiências fenomenológicas da Psicologia Humanista (Zahavi, 2019), da qual Rogers é somente um representante, decorre de um entendimento, ou suposta expectativa, de que essa perspectiva seja ou esboce um projeto de Psicologia Fenomenológica. Contudo, isso não foi uma preocupação central dos psicólogos humanistas que se apropriam de elementos da Fenomenologia e de sua visão de mundo para compor a sua ciência, que é aplicada e empírica. Ademais, dependendo da abordagem humanista, é possível perceber influências de outros saberes além da Fenomenologia, como Pragmatismo, Funcionalismo, psicanálises freudiana e pós-freudianas, Daseinanálise, Psicodrama, paradigmas positivistas, holísticos, sistémicos etc. (Castelo Branco, 2019).

8. A despeito disso, no cenário brasileiro acadêmico de formação profissional, é fato que a atitude fenomenológica é ensinada em disciplinas relacionadas às psicologias humanistas, a partir de diversos entendimentos não necessariamente comuns (Orengo et al., 2020). Apesar das críticas, está estabelecido um cenário que permite a circulação e disseminação do legado husserliano fora da Filosofia. 
9. Finalmente, é possível observar que os psicólogos têm recorrido a uma intelecção meta-teórica, inspirada por Husserl (1929/1992) e Rogers (1957/2008; 1959/1977), para pensar o que seria suspenso pela consideração positiva incondicional. A Fenomenologia, por um lado, é uma filosofia autorreflexiva, ou seja, não precisa de sujeitos empíricos para se voltar à ideia de um fenômeno, analisando como os sentidos aparecem para a experiência consciente (Husserl, 1913/2006). A abordagem de Rogers (1961/1997), por outro lado, é uma Psicologia aplicada que, dependendo do contexto interventivo, objetiva mudar a personalidade do cliente, gerar aprendizagens significativas e proporcionar relações de encontro e crescimento intra e interpessoal. Por isso, Rogers trabalha com sujeitos empíricos e precisa deles para construir e executar suas intervenções em nível de experiência. Enquanto a Fenomenologia proporciona uma análise da experiência em primeira pessoa, a Psicologia rogeriana compreende a experiência na terceira pessoa.

Na prática clínica da consideração positiva incondicional, há um constante exercício de atenção do terapeuta ao que o cliente expressa, com o cuidado de não julgar suas expressões, pensamentos e valores, para não confundir suas experiências com as dele. $\mathrm{O}$ que seria, então, suspenso? Os julgamentos que emanam dos afetos do terapeuta que emergem a partir do que as expressões alheias lhe provocam. Se a expressão do cliente afeta o terapeuta de modo que isso seja atestado pela sua experiência, decorre uma reação de sim-patia em que as experiências do terapeuta são identificadas com aquelas do cliente. Por isso, surgem reações de concordância e supervalorização que podem gerar alegria e cumplicidade. Se tais expressões não condizem com a experiência do terapeuta e são contestadas por ele, incorre uma anti-patia com reações de discordância e desvalorização, que podem acarretar em raiva e frustração no encontro com o outro. Se não afeta em termos de sim-patia ou anti-patia, pode ocorrer uma a-patia, uma falta de interesse ou indiferença ante a experiência do outro. Isso pode gerar cansaço ou tédio.

Essas reações afetivas, em comum, são parte da experiência do terapeuta naquilo que ele foi afetado pela manifestação do outro. Ao ficar preso nisso, o terapeuta tende a acreditar que os juízos e valores que emergem de sua experiência representam aquilo que o cliente é por si, desatentando para o evento de que isso é um dado da relação e que esses afetos e juízos procedem da sua experiência e não do cliente. Isso seria uma leitura do que poderia ser uma atitude natural na relação terapêutica. Considerar positiva e incondicionalmente a experiência do outro implica em abordar a experiência alheia como um lócus de verdade e conhecimento válido. Eis a dimensão de positivar (não no sentido de reforçar) a experiência do cliente, não impondo pré-condições para se relacionar com ele, mas deixando-o ser quem é. 
Se entendida como uma atitude de suspensão, a consideração positiva incondicional é um exercício de atenção sobre: o que o cliente expressa ao terapeuta; o que isso lhe provoca em termos de afetos simpático, antipático e apático; quais os conteúdos e juízos emergem disso. Assim, se reconhece esses juízos como procedentes da experiência do terapeuta e não do cliente, entendendo que este não é assim por si só. Retira-se de ação tais juízos, suspendendo-os, pois se entende que o que está em voga no momento terapêutico é a experiência do cliente. Ao ficar preso no fluxo desses juízos, o terapeuta permanece em sua experiência não se descentrando dela para ir até o outro. Por isso, o exercício de considerar positiva e incondicionalmente o outro se articula com a condição de compreensão empática, que apreende os sentidos e significados da experiência do cliente a partir do seu referencial e não do terapeuta. Aquilo que foi suspenso, no entanto, pode retornar em outro momento. Neste caso, cabe uma (auto)supervisão para examinar o que tais afetos e juízos significam para o terapeuta e como eles estão afetando o processo terapêutico, dificultando o centramento no outro.

A partir do argumento de Zahavi (2019), portanto, aponta-se que a ideia de entender a consideração positiva incondicional como uma epoché decorre mais de uma necessidade de substanciar fenomenologicamente o que Rogers fez, do que propor uma Fenomenologia pura que culmine em uma filosofia fenomenológica da personalidade ou da pessoa, que sirva como horizonte para fundamentar sua teoria e prática. Antes disso, a condição rogeriana de consideração positiva incondicional seria um bom exemplo da atitude de não julgamento, contato e descrição da experiência sem epoché fenomenológica. Como um recurso da escuta clínica, essa condição facilita e possibilita que as idiossincrasias do cliente se apresentem e permitam ao psicólogo compreender a experiência alheia.

\section{Considerações Finais}

Este artigo refletiu os limites da ideia da consideração positiva incondicional como uma epoché fenomenológica. Para isso, definiu em que consistem essas noções e, posteriormente, situou as origens da ideia da epoché como uma atitude clínica, e da consideração positiva incondicional como uma atitude de suspensão fenomenológica. Desse transcurso, estabeleceram-se nove apontamentos relacionados às duas atitudes.

Em uma síntese conclusiva, o que seria suspenso pela a consideração positiva incondicional? Os juízos que procedem dos afetos de simpatia, apatia e antipatia. Isso seria uma meta-teoria a Husserl e Rogers para descrever como ocorre o fenômeno da escuta não- 
diretiva sem julgamentos, a qual partiria da apropriação de um elemento (epoché) que demarca uma apropriação da visão de mundo oriunda da Fenomenologia, mas não se trata de um método fenomenológico, condição para uma Fenomenologia pura, uma filosofia fenomenológica ou mesmo uma Psicologia Fenomenológica. A consideração positiva incondicional é uma atitude clínica de escuta que se desenvolveu fora do método fenomenológico. De tal modo, pensar a consideração positiva incondicional como uma atitude de epoché é desnecessário, pois ela não é ou se propõe a ser o a-priori de nenhuma Fenomenologia pura nem se desdobra em uma redução fenomenológica, tampouco precisa disso para ser legitimada. Logo, a suspensão rogeriana não é fenomenológica e a consideração positiva incondicional não suspende de início a crença na tendência à autorrealização.

Percebe-se que se epistemologicamente é conflitante misturar a Fenomenologia de Husserl com a Psicologia Humanista de Rogers, historicamente é possível compreender que esse movimento produziu um conhecimento local que gera um impulso criativo e formativo em suas contendas - basta atentar para os variados artigos que foram referidos neste texto. Assim, o pensamento da consideração positiva incondicional como uma atitude de epoché, tem o papel de provocar constantes reexames nas teorias rogerianas e fenomenológicas e trazer esclarecimentos para os psicoterapeutas que afirmam trabalhar com atitudes fenomenológicas e para os docentes que ensinam disciplinas humanistas e fenomenológicas. Outros elementos dos saberes rogeriano e husserliano podem ser trabalhados em novos exercícios reflexivos sobre suas articulações, como as questões da compreensão empática e do eu (self-ego). Além disso, ponderações concernentes às articulações existentes entre o pensamento de Rogers e outras fenomenologias podem gerar novas discussões sobre suas (im)possibilidades e limites.

\section{Referências}

Amatuzzi, M. (1989). O significado da psicologia humanista, posicionamentos filosóficos implícitos. Arquivos Brasileiros de Psicologia, 41(4), 88-95. Recuperado de http://bibliotecadigital.fgv.br/ojs/index.php/abp/article/view/21723/20476

Amatuzzi, M. M., \& Carpes, M. (2010). Aspectos fenomenológicos do pensamento de Rogers. Memorandum: Memória E História Em Psicologia, 19, 11-25. doi:10.35699/1676-1669.2010.6567 
Almeida, L. (2009). Consideração Positiva Incondicional no sistema teórico de Carl Rogers. Temas em Psicologia, 17(1), 177-190. Recuperado de http://pepsic.bvsalud.org/pdf/tp/v17n1/v17n1a15.pdf

Araújo, I., \& Freire, J. (2014). Os valores e a sua importância para a teoria da clínica da abordagem centrada na pessoa. Revista da Abordagem Gestáltica, 20(1), 86-93. Recuperado de http://pepsic.bvsalud.org/pdf/rag/v20n1/v20n1a12.pdf

Castelo Branco, P. (2019). Fundamentos epistemológicos da abordagem centrada na pessoa. Rio de Janeiro: Via Verita.

Castelo Branco, P., \& Cirino, S. (2016). Reflexões sobre a consciência na fenomenologia e na abordagem centrada na pessoa. Gerais: Revista Interinstitucional de Psicologia, 9(2), 241-258. Recuperado de http://pepsic.bvsalud.org/pdf/gerais/v9n2/v9n2a07.pdf

Castelo Branco, P., \& Cirino, S. (2017). Fenomenologia nas obras de Carl Rogers: Apontamentos para o cenário brasileiro. Revista de Psicologia, 8(2), 44-52. Recuperado de http://www.periodicos.ufc.br/psicologiaufc/article/view/6719

Castro, T., \& Gomes, W. (2011). Movimento fenomenológico: Controvérsias e perspectivas na pesquisa psicológica. Psicologia: Teoria e Pesquisa, 27(2), 233-240. doi:10.1590/S0102-37722011000200014

Combs, A. (1948). Phenomenological concepts in nondirective therapy. Journal of Consulting Psychology, 12(4), 197-267. doi:10.1037/h0061905

Feijoo, A. (2013). Bases do pensamento fenomenológico e existencial em William James. Psicologia: Ciência e Profissão, 33(4), 840-851. doi:10.1590/S141498932013000400006

Forghieri, Y. (1993). Psicologia Fenomenológica: Fundamentos, método e pesquisas. São Paulo: Pioneira.

Gomes, W., \& Castro, T. (2010). Clínica fenomenológica: Do método de pesquisa para a prática psicoterapêutica. Psicologia: Teoria e Pesquisa, 26(spe), 81-93. doi:10.1590/S0102-37722010000500007

Goto, T. A. (2015). Introdução à Psicologia fenomenológica: A nova Psicologia de Edmund Husserl. São Paulo: Paulus.

Goto, T., \& Feijoo, A. (2017). É Possível a Fenomenologia de Husserl como Método de Pesquisa em Psicologia?. Psicologia: Teoria e Pesquisa, 32(4). doi:10.1590/0102.3772e3241 
Goto, T., Holanda, A., \& Costa, I. (2018). Fenomenologia transcendental e a psicologia fenomenológica de Edmund Husserl. Revista do NUFEN, 10(3), 38-54. doi:10.26823/RevistadoNUFEN.vol10.n03artigo35

Holanda, A. (1997). Fenomenologia, psicoterapia e psicologia humanista. Estudos de Psicologia (Campinas), 14(2), 33-46. doi:10.1590/S0103-166X1997000200004

Husserl, E. (1992). Conferências de Paris (A. Fidalgo \& A. Mourão, Trads.). Lisboa: Edições 70. (Obra original publicada em 1929)

Husserl, E. (2001). Meditações cartesianas: Introdução à fenomenologia (F. Oliveira, Trad.). São Paulo: Madras. (Obra original publicada em 1931)

Husserl, E. (2006). Ideias para uma Fenomenologia pura e para uma Filosofia fenomenológica: Introdução geral à Fenomenologia pura (2a ed., M. Susuki, Trad.). Aparecida, SP: Ideias \& Letras. (Obra original publicada em 1913)

May, R. (2000). A psicologia e o dilema humano (C. Soares, Trad.). Rio de Janeiro: Vozes. (Obra original publicada 1979)

Moreira, V. (2009). A Gestalt-Terapia e a Abordagem Centrada na Pessoa são enfoques fenomenológicos? Revista da abordagem Gestáltica, 15(1), 03-12. Recuperado de http://pepsic.bvsalud.org/pdf/rag/v15n1/v15n1a02.pdf

Moreira, V. (2010). Possíveis contribuições de Husserl e Heidegger para a clínica fenomenológica. Psicologia em Estudo, 15(4), 723-731. doi:10.1590/S141373722010000400008

Orengo, F., Holanda, A., \& Goto, T. (2020). Fenomenologia e psicologia fenomenológica para psicólogos brasileiros: Uma compreensão empírica. Psicologia em Estudo, 25, 01-16. doi:10.4025/psicolestud.v25i0.45065

Rogers, C. (1977). Teoria e pesquisa. In C. Rogers \& M. Kinget, Psicoterapia e relações humanas: Teoria e prática da terapia não-diretiva (Vol. 1., pp. 143-274, M. Bizzotto, Trad.). Belo Horizonte: Interlivros. (Obra original publicada em 1959)

Rogers, C. (1997). Tornar-se pessoa (M. Ferreira \& A. Lamparelli, Trads.). São Paulo: Martins Fontes. (Obra original publicada em 1961)

Rogers, C. (2008). As condições necessárias e suficientes para mudança terapêutica de personalidade. In J. Wood et al. (Orgs.), Abordagem centrada na pessoa (pp. 143161). Vitória: EDUFES. (Obra original publicada em 1957)

Sokolowski, R. (2010). Introdução à fenomenologia (A. Moraes, Trad.). São Paulo: Edições Loyola. (Obra original publicada em 2000) 
Stein, E. (2019). A fenomenologia e seu significado de visão de mundo. In E. Stein, Textos sobre Husserl e Tomás de Aquino (pp. 137-164, E. Giachi, G. Santos., J. Filho., M, Schuback \& U. Matthias, Trads.). São Paulo: Paulus. (Obra original publicada em 1930-1931)

Van Kaam, A. (2018). Análise fenomenal: Exemplificada por um estudo da experiência de "realmente se sentir compreendido" (A. Nobre \& W. Gomes, Trads.). Revista da Abordagem Gestáltica, 24(2), 260-264. doi:10.18065/RAG.2018v24n2.14. (Obra original publicada em 1959)

Zahavi, D. (2019). Fenomenologia aplicada: Porque é seguro ignorar a epoché (V. Portugal, Trad.). Revista da Abordagem Gestáltica, 25(3), 332-341. doi:10.18065/RAG.2019v25n3.12

\section{Endereço para correspondência}

\section{Paulo Coelho Castelo Branco}

Universidade Federal da Bahia

Programa de Pós-Graduação em Psicologia da Saúde

Rua Hormindo Barros, 58, Candeias, Vitória da Conquista - BA, Brasil. CEP 45029-094

Endereço eletrônico: pauloccbranco@gmail.com

Recebido em: 04/11/2019

Reformulado em: 09/06/2020

Aceito em: 04/09/2020

\section{Notas}

*Doutor em Psicologia pela UFMG, docente do Programa de Pós-Graduação em Psicologia da Saúde da UFBA.

Este artigo de revista Estudos e Pesquisas em Psicologia é licenciado sob uma Licença Creative Commons Atribuição-Não Comercial 3.0 Não Adaptada. 